\title{
PROCEDIMENTOS PARA A OBTENÇÃO DO PAGAMENTO POR SERVIÇOS AMBIENTAIS NO ÂMBITO DA INSTITUIÇÃO DE UMA RESERVA PARTICULAR DO PATRIMÔNIO NATURAL
}

\author{
Fabio Leandro da Silva ${ }^{1}$ \\ Caroline Picharillo ${ }^{2}$ \\ Leonardo Gallo Macera ${ }^{3}$ \\ Jéssica de Almeida Monteiro ${ }^{4}$ \\ Renata Bovo Peres 5
}

\section{RESUMO}

A Reserva Particular do Patrimônio Natural (RPPN) é uma unidade de conservação de uso sustentável, a qual tem por objetivo promover a proteção dos recursos naturais em terras privadas. Uma alternativa para estimular os proprietários de terra a criarem uma RPPN é através da adoção ao Pagamento por Serviços Ambientais (PSA). Desse modo, o presente trabalho tem por objetivo verificar a possibilidade de tornar um fragmento de vegetação nativa, localizado no sítio São João - município de São Carlos (SP), em uma RPPN e, assim, estimar o valor do PSA que poderia ser recebido. A metodologia envolveu a revisão de dispositivos normativos pertinentes ao processo de criação da RPPN; a caracterização física da microbacia hidrográfica do Ribeirão do Feijão, onde o sítio São João está localizado; e a estimativa do valor do PSA. O fragmento de vegetação nativa no sítio $(4,76$ hectares) é passível de se tornar uma RPPN; e o valor estimado para o PSA foi de $\mathrm{R} \$ 1.517,25$ por ano. De modo geral, verificou-se que a burocracia e a lentidão dos processos de abertura dos editais contribuem para o desestímulo dos proprietários rurais em aderir a tais procedimentos.

Palavras-chave: gestão ambiental privada, incentivo econômico, legislação ambiental, propriedade rural, unidades de conservação.

\footnotetext{
${ }^{1}$ Graduado em Gestão e Análise Ambiental. Mestrando em Ciências da Engenharia Ambiental (EESC/USP). E-mail: fabioleodasilva@gmail.com

${ }^{2}$ Graduada em Gestão e Análise Ambiental. Mestranda em Ciências da Engenharia Ambiental (EESC/USP). E-mail: carol.gestao012@gmail.com

${ }^{3}$ Graduado em Gestão e Análise Ambiental. Mestrando em Engenharia Ambiental (Universidad Politécnica de Madrid). E-mail: leonardo.macera@hotmail.com

${ }^{4}$ Graduada em Gestão e Análise Ambiental. E-mail: jessica.monteiro@terra.com.br

${ }_{5}$ Graduada em Arquitetura e Urbanismo. Mestre em Arquitetura e Urbanismo. Doutora em Engenharia Urbana. Professora do Curso de Bacharelado em Gestão e Análise Ambiental e do Programa de PósGraduação em Ciências Ambientais (PPGCam) da Universidade Federal de São Carlos (UFSCar). E-mail: renataperes@ufscar.br.
} 


\title{
PROCEDURES FOR OBTAINING THE PAYMENT FOR ENVIRONMENTAL SERVICES IN THE AMBIT OF INSTITUTION OF A PRIVATE RESERVE NATURAL HERITAGE
}

\begin{abstract}
The Private Natural Heritage Reserve (PNHR) is a protected area of sustainable use that has the goal to promote the protection of natural resources in private land. An alternative to encourage the landowners to create a PNHR is through the Payment for Environmental Services (PES). In this way, this study aims to verify the possibility to turn a fragment of native vegetation, which is located in São João ranch - city of São Carlos (SP - Brazil), into a PNHR and, then estimate the PES value that could be received. The methodology involved the review of the regulatory provision about the process of creation of a PNHR; the physical characterization of the Ribeirão Feijão whatershed, where the study area is located; and the estimation of the PES value. The fragment of native vegetation in the ranch (4.76 hectares) is capable to become a PNHR; and the estimated value of PES was $\mathrm{R} \$ 1.517,25$ per year. In general, we verified that the bureaucracy and the slowness of the opening of processes notices have contributed to the discouragement of rural land owner's to adhere these procedures.
\end{abstract}

Keywords: economics incentives, environmental legislation, private environmental management, protected areas, rural property.

\section{INTRODUÇÃO}

A proteção dos recursos naturais de um país ou região é um fato aceito mundialmente nos dias de hoje como forma de preservar as funcionalidades dos ecossistemas, aquáticos e terrestres, resguardando sua diversidade biológica e os serviços ambientais (SCHENINI; COSTA; CASARIN, 2004). De acordo com o relatório internacional "Millennium Ecosystem Assessment", serviços ambientais, ou serviços ecossistêmicos, são definidos como os benefícios adquiridos pelas sociedades humanas através dos ecossistemas (MA, 2005), tais como abastecimento de água, conservação do solo, alimentos, manutenção da qualidade do ar, medicamentos, polinização, entre outros (EMBRAPA, 2015).

Tal proteção só poderá ser efetivamente realizada com a preservação de parcelas significativas de seus espaços naturais. Em razão disto, no Brasil, e a exemplo de outros países, são criadas diversas Unidades de Conservação (UC's), visando, além da proteção dos recursos bióticos, a conservação dos serviços ambientais (SCHENINI; COSTA; CASARIN, 2004).

Por unidade de conservação (UC) se entende:

"(...) espaços territoriais e seus recursos ambientais, incluindo as águas jurisdicionais, com características naturais relevantes, legalmente instituídos pelo Poder Público, com objetivos de conservação e limites definidos, sob regime especial de administração, ao qual se aplicam garantias adequadas de proteção da lei " (BRASIL, 2000). 
A definição de UC's foi apresentada pelo Instituto Brasileiro de Meio Ambiente e dos Recursos Naturais Renováveis (IBAMA), quando da instituição do Sistema de Unidades de Conservação da Natureza (SNUC), através da Lei Federal n 9.985, de 19 de julho de 2000, que estabelece critérios e normas para a criação, implantação e gestão destas unidades.

O SNUC define duas categorias distintas de UC's: Unidades de Proteção Integral e Unidades de Uso Sustentável. As Unidades de Proteção Integral têm como principal característica o uso indireto dos recursos naturais, não sendo permitido o consumo e a coleta dos mesmos; já as Unidades de Uso Sustentável, caracterizam-se pelo uso direto dos recursos, ou seja, envolve a coleta e o uso (BRASIL, 2000).

Dentre as Unidades de Conservação de Uso Sustentável destaca-se a chamada Reserva Particular do Patrimônio Natural (RPPN). As RPPN's estão localizadas em terras particulares, sob o domínio privado, de caráter voluntário, e gravadas com perpetuidade. Outro ponto peculiar das RPPN's diz respeito a seu objetivo, ou seja, apesar de sua categorização como unidade de uso sustentável, não são permitidas atividades exploratórias nestas áreas (BRASIL, 2000).

Os benefícios da criação de uma RPPN para o proprietário rural envolvem: a exclusão da área instituída como RPPN da área tributável para o cálculo do Imposto Territorial Rural (ITR); a prioridade em programas de crédito rural (BRASIL, 2000; SÃO PAULO, 2006); e o desenvolvimento de outras fontes de renda, tal como o ecoturismo (CERETTA; SANTOS, 2013). Para o ecossistema e para a sociedade, os benefícios também são muitos: o fortalecimento dos sistemas de áreas protegidas; o apoio à pesquisas científicas; o apoio às atividades de educação ambiental; a possibilidade de aumento da conectividade da paisagem natural; a proteção dos serviços ambientais; e a proteção de áreas-chave ao longo dos biomas (PELLIN; RANIERI, 2009).

No Brasil, a criação de uma RPPN vem se destacando nos últimos anos, sendo que até fevereiro de 2015 registrou-se um total de 782 RPPN's no país (MMA, 2015). Entretanto, a falta de incentivos para sua criação, assim como a burocracia ligada ao seu reconhecimento, têm contribuído para o desestímulo dos proprietários rurais em adotá-la (PELLIN; RANIERI, 2009). Neste contexto, a Resolução SMA no 89/2013, institui, no âmbito do Estado de São Paulo - Brasil, o Projeto PSA/RPPN, o qual tem por finalidade disponibilizar recursos públicos para a conservação e restauração dos processos ecológicos nas RPPN's. Deste modo, o proprietário rural habilitado para instituir uma RPPN em suas terras poderá receber recursos financeiros, por meio do instrumento econômico Pagamento por Serviços Ambientais (PSA), como auxílio à manutenção da mesma.

O instrumento econômico PSA surge, portanto, como uma alternativa para minimizar ou eliminar o risco à perda dos serviços ambientais em terras privadas (EMBRAPA, 2015), favorecendo, assim, a criação de RPPN's. Para Jack, Kousky e Sims (2008), políticas públicas baseadas em incentivos financeiros direcionam as externalidades, de modo que os donos de terras decidam por eles mesmos mudar seu comportamento.

Wunder (2005) define PSA da seguinte forma: transação voluntária onde um serviço ambiental é "comprado" por, pelo menos, um beneficiário do serviço, de pelo menos um fornecedor do serviço, se e somente se este fornecedor garantir a provisão do mesmo (i.e. característica esta denominada condicionalidade). É importante destacar que quando a proteção de um serviço ambiental é considerada como um benefício público (e.g. conservação de mananciais), atendendo o maior número de beneficiários possíveis, os custos de transação tornam-se menores 
(ENGEL; PAGIOLA; WUNDER, 2008), o que pode contribuir efetivamente com o aumento da adesão aos programas de PSA.

O presente trabalho tem por objetivo verificar a possibilidade de tornar um fragmento de vegetação nativa, localizado no sítio São João - município de São Carlos (SP), em uma RPPN, e, posteriormente, estimar o valor do PSA que poderia ser recebido.

\section{MÉTODO}

\section{1 ÁREA DE ESTUDO}

A área de estudo do presente trabalho corresponde a um fragmento de vegetação nativa no sítio São João, localizado no município de São Carlos, interior do Estado de São Paulo - Brasil (Figura 01). 
Figura 1 - Localização do sítio São João, São Carlos (SP).

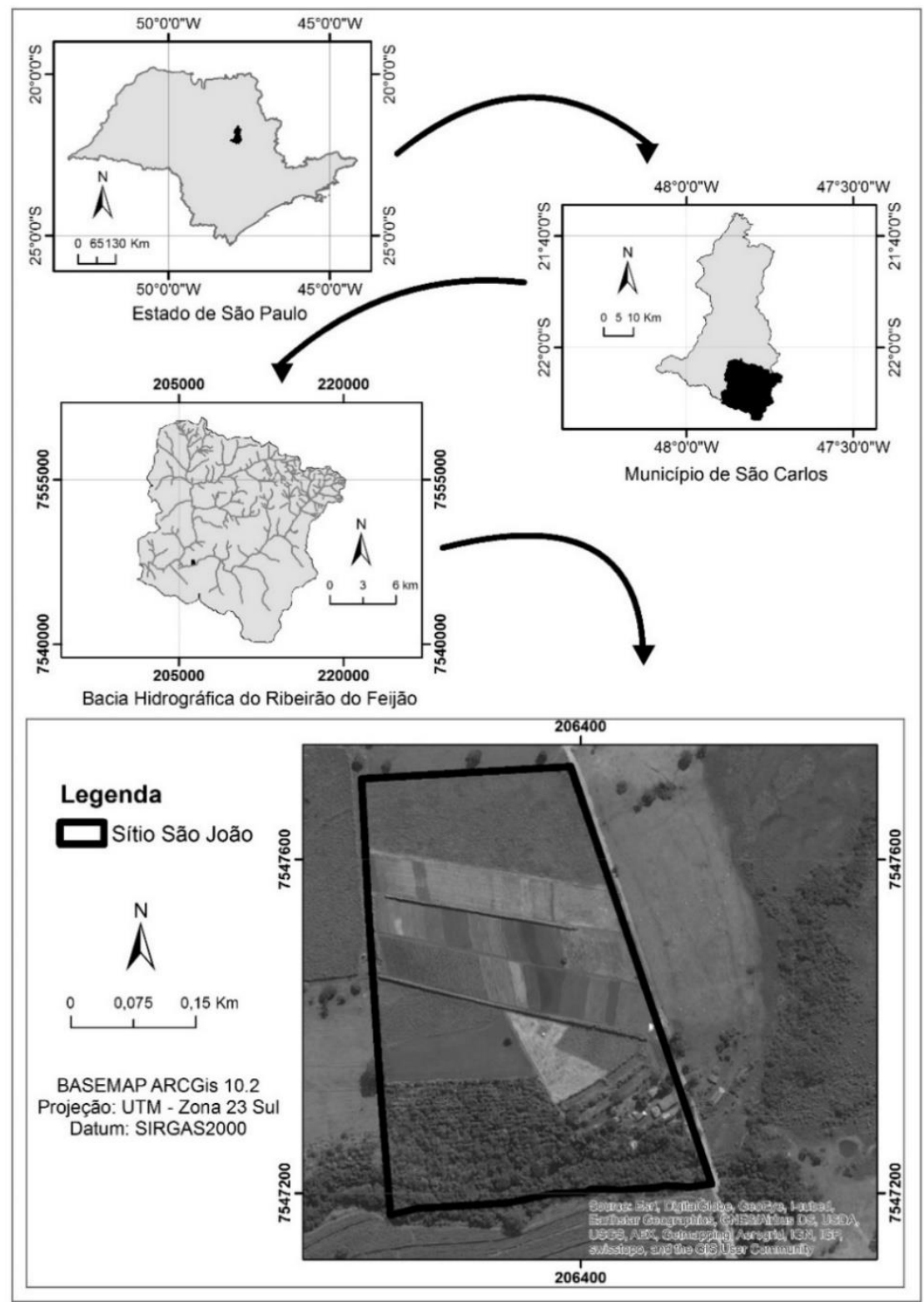

Fonte: Elaborado pelos autores.

Esta propriedade de 14 hectares tem como principal atividade econômica a agricultura familiar. Além disto, o sítio São João é também conhecido por desenvolver atividades de educação ambiental e por incentivar a preservação do manancial Ribeirão do Feijão (EF, 2016). O sítio está inserido na microbacia 
hidrográfica do Ribeirão do Feijão, principal manancial de abastecimento público do município de São Carlos (MACHADO; DUPAS, 2013). A criação de uma RPPN poderá contribuir efetivamente com o aumento da proteção dos recursos naturais ali existentes, bem como proporcionar meios para a continuidade dos projetos de educação ambiental desenvolvidos no local.

\subsection{PROCEDIMENTOS METODOLÓGICOS}

Os procedimentos metodológicos deste trabalho foram divididos em três etapas de execução.

A primeira etapa correspondeu à revisão de leis, decretos e portarias pertinentes à instituição de RPPN's no Brasil e no Estado de São Paulo, com a finalidade de se obter um panorama dos processos de desenvolvimento e implantação de uma RPPN.

A segunda etapa referiu-se à caracterização dos aspectos físicos e ambientais da microbacia hidrográfica do Ribeirão do Feijão, onde o sítio está inserido, a qual contribuiu efetivamente para a delimitação da RPPN. Para tanto, foram elaborados mapas temáticos de Hidrografia, Declividade, Tipologias Ocupacionais e Vegetação Natural, no ambiente SIG (Sistema de Informação Geográfico) ArcGIS 10.2 do Environmental Systems Research Institute (ESRI).

Os mapas temáticos de Declividade e de Hidrografia foram elaborados a partir da vetorização das cartas topográficas SF-23-Y-A-I-1 (São Carlos) e SF-23-YA-I-2 (Corumbataí), obtidas do banco de dados do Instituto Brasileiro de Geografia e Estatística - IBGE (<http://loja.ibge.gov.br/catalog/category/view/s/cartas-mapas-ecartogramas/id/15/).

As classes de declividade foram adaptadas do trabalho de Biasi (1992), o qual atribui, para cada intervalo de declividade, o uso do solo mais adequado para aquele intervalo, a fim de evitar os movimentos de massa. Deste modo, as classes definidas foram: < 5\% (uso antrópico com restrições); de 5\% a 12\% (limite máximo de mecanização agrícola); $12 \%$ a $30 \%$ (limite máximo de urbanização); > 30\% (exploração da terra permitida somente se sustentada por cobertura vegetal).

O mapa temático de Tipologias Ocupacionais foi produzido a partir da digitalização da imagem orbital do sensor OIL (Operational Land Imager), abordo do satélite LANDSAT 8, datada de 23/04/2015 (órbita ponto: 220/75), obtida do United States Geological Survey (USGS). As tipologias ocupacionais foram definidas de acordo com o estabelecido pelo IBGE (2013), sendo: Área de Vegetação Natural, Área Descoberta, Área Urbanizada, Corpo d'água continental (i.e. represas e reservatórios), Lavoura Permanente, Lavoura Temporária, Pastagem e Silvicultura.

O mapa temático de Vegetação Natural, por sua vez, foi obtido a partir do recorte do mapa de tipologias ocupacionais, com a finalidade de destacar os fragmentos de vegetação existentes na microbacia.

Por fim, a terceira etapa metodológica foi estimar o valor do PSA destinado ao proprietário do sítio São João, caso a RPPN fosse instituída. Tal estimativa foi baseada nos termos previstos no Anexo da Resolução SMA 89/2013 (SÃO PAULO, 2013), os quais estabelecem o processo de obtenção do valor do PSA. Tal processo é composto basicamente por duas etapas: Cálculo do Valor de Referência Anual (VRA) e o Cálculo do Pagamento por Serviços Ambientais (PSA). O valor do VRA é calculado da seguinte forma:

Onde:

$$
\text { VRA }=\text { CV } \times \text { UFESP } \times \text { Fator RPPN }
$$

CV = Coeficiente de Valoração (Definido no edital nํ01/2013/CAP/RPPN) 
UFESP $=$ Unidade Fiscal do Estado de São Paulo.

Fator RPPN $=[1+$ (fator de importância + fator de ameaça) /4]

O "Fator RPPN" engloba duas sub variáveis: o fator de importância (Fimp) e o fator de ameaça (Fam). Para estabelecer o Fimp, deve-se guiar por uma chave de determinação com perguntas sequenciais e respostas binárias (i.e. Sim ou Não) para cada questão. A partir de uma resposta negativa segue-se para a pergunta subsequente; quando a resposta for afirmativa encontra-se o valor referente a este fator. Já o Fam varia de 0 (nenhuma ameaça) a 1 (todas as ameaças), sendo obtido pela soma dos pontos atribuídos às ameaças sofridas no local, dentre um rol de cinco possíveis ameaças.

Após o cálculo do VRA, o PSA é obtido. Inicialmente, a área total da RPPN é dividida em classes de tamanho (CLASSE). Cada CLASSE tem seu coeficiente de área $(\mathrm{Ca})$. O resultado da multiplicação de todas as classes de tamanho da RPPN pelos respectivos coeficientes de área é somado e, posteriormente, multiplicado pelo VRA. Destaca-se que o limite máximo da CLASSE e o coeficiente de área para cada CLASSE foram definidos pelo edital $n \div 01 / 2013 / C A P / R P P N$.

\section{RESULTADOS E DISCUSSÕES}

\subsection{ETAPA 1: A INSTITUIÇÃO DE UMA RPPN - PROCESSOS E NORMAS}

No Estado de São Paulo, o processo de instituição de uma RPPN é realizado pela Secretaria Estadual de Meio Ambiente (SMA). Todavia, o pedido de instituição e envio da documentação do proprietário ou pessoa jurídica interessada deve ser encaminhado para a Fundação Florestal (FF); salienta-se que se a FF não emitir um parecer favorável à criação da RPPN, o trâmite chega ao fim. O procedimento necessário para a criação de uma RPPN paulista está representado na Figura 2.

A Tabela 1, por sua vez, resume a legislação ambiental aplicável para a criação de uma RPPN no Estado de São Paulo, incluindo incentivos fiscais para aqueles que conservam a natureza e a instrução normativa para fins de isenção do ITR.

Figura 2 - Procedimentos para a criação de uma RPPN paulista.

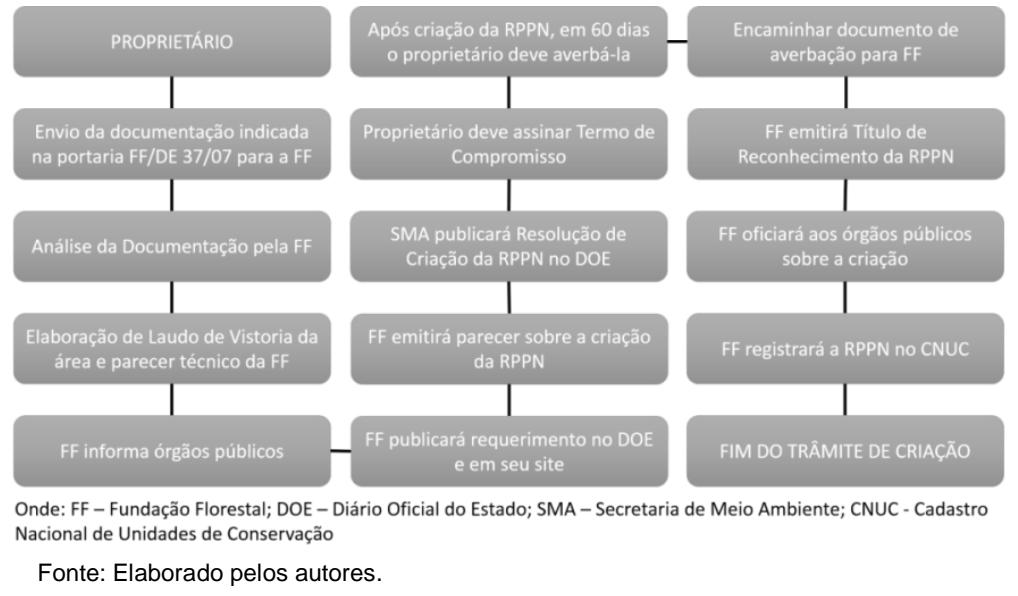


Tabela 1 - Legislação vigente do Estado de São Paulo sobre a criação de RPPN

\begin{tabular}{|c|c|}
\hline Dispositivos & Descrição \\
\hline $\begin{array}{l}\text { Decreto Estadual } n^{\circ} 51.150 \text {, de } 3 \\
\text { de outubro de } 2006\end{array}$ & $\begin{array}{l}\text { Dispõe sobre o reconhecimento das RPPN's, no âmbito } \\
\text { do Estado de São Paulo, institui o Programa Estadual } \\
\text { de Apoio às RPPN's e dá providências correlatas. }\end{array}$ \\
\hline $\begin{array}{l}\text { Portaria Normativa FF/DE n } 37 \\
\text { de } 22 \text { de fevereiro de } 2007\end{array}$ & $\begin{array}{l}\text { Estabelece procedimentos para a criação das RPPN's } \\
\text { Estaduais. }\end{array}$ \\
\hline $\begin{array}{l}\text { Resolução SMA nº } 89 \text {, de } 18 \text { de } \\
\text { setembro de } 2013\end{array}$ & $\begin{array}{l}\text { Institui as diretrizes para a execução do Projeto de } \\
\text { Pagamento por Serviços Ambientais para as Reservas } \\
\text { Particulares do Patrimônio Natural - RPPN, no âmbito } \\
\text { do Programa de Remanescentes Florestais. }\end{array}$ \\
\hline $\begin{array}{l}\text { Decreto Estadual no } 59.260 \text {, de } \\
05 \text { de junho de } 2013\end{array}$ & $\begin{array}{l}\text { Institui o Programa Estadual de apoio financeiro a } \\
\text { ações ambientais, denominado Crédito Ambiental } \\
\text { Paulista. }\end{array}$ \\
\hline $\begin{array}{l}\text { Decreto Estadual n } 60.302 \text {, de } \\
27 \text { de março de } 2014\end{array}$ & $\begin{array}{l}\text { Institui o Sistema de Informação de Gestão de Áreas } \\
\text { Protegidas e de Interesse Ambiental do Estado de São } \\
\text { Paulo - SIGAP e dá providências correlatas. }\end{array}$ \\
\hline $\begin{array}{l}\text { Instrução Normativa n } 5 \text {, de } 25 \\
\text { de março de } 2009\end{array}$ & $\begin{array}{l}\text { Padroniza o modelo de Ato Declaratório Ambiental - } \\
\text { ADA, considerando a necessidade de regulamentação } \\
\text { das modalidades de apresentação do ADA, para fins de } \\
\text { isenção do ITR }\end{array}$ \\
\hline
\end{tabular}

Fonte: FF (2007), IBAMA (2009), São Paulo (2006; 2013a; 2013b, 2014).

As RPPN's passam a ser reconhecidas no Estado de São Paulo por meio do Decreto Estadual $n^{\circ} 51.150$, de 03 de outubro de 2006, também responsável pela instituição do programa de apoio às RPPN's paulistas.

A Portaria Normativa FF/DE $n^{\circ} 37$ de 2007 em seu art. $1^{\circ}$ dispõe sobre os processos para pedidos de reconhecimento das RPPN's estaduais. A Resolução SMA n' 89 institui o Programa por Serviços Ambientais para as RPPN's, através do Crédito Ambiental Paulista (instituído Decreto Estadual no 59.260, de 05 de junho de 2013), mediante a supervisão da Coordenadoria de Biodiversidade e Recursos Naturais.

O Decreto $\mathrm{n}^{\circ}$ 60.302, de 27 de março de 2014 busca estimular a conservação da diversidade biológica e o uso sustentável de recursos naturais em terras de propriedade pública ou privada, contribuindo com a conservação genética "in situ" de espécies de fauna e flora (Art. $2^{\circ}$ ).

Conforme o Decreto $n^{\circ} 51.150$, de 03 de outubro de 2006, a gestão conjunta da FF do Estado de São Paulo, com órgãos competentes nas esferas do poder (i.e. federal, estadual e municipal), tem como objetivo alcançar isenções tributárias para RPPN's. O instrumento legal Ato Declaratório Ambiental consiste em um cadastro pelo qual o proprietário de terra tem a possibilidade de reduzir o ITR em até $100 \%$ da área protegida (e.g. RPPN, Área de Servidão Florestal) através do cadastramento da propriedade rural junto ao Instituto Brasileiro do Meio Ambiente e dos Recursos Naturais Renováveis (IBAMA, 2009; 2016).

Ainda no que se refere sobre normas brasileiras relacionadas com UC's, inclusive RPPN's, destacam-se aquelas que dispõem sobre aspectos do licenciamento ambiental de empreendimentos que podem ocasionar efeitos adversos à estas unidades.

A Resolução CONAMA n 428/2010 dispõe que atividades de significativo impacto ambiental que podem ocasionar danos à uma RPPN, poderá obter a primeira licença ambiental do órgão licenciador mediante a autorização do órgão 
criador da RPPN. Quando o órgão licenciador considerar que a atividade de significativo impacto ambiental afetará uma Unidade de Conservação (e.g. RPPN) tendo como base o Estudo de Impacto Ambiental (EIA), a UC afetada deve ser uma das unidades beneficiárias da compensação ambiental que será derivada do processo de licenciamento (Lei $n^{\circ}$ 9.985/2000, art. 36, § 3ํ).

Por sua vez, a compensação ambiental é calculada (Decreto $n^{\circ} 6.848$ de 14 de maio de 2009, art. 31) através do produto do grau de impacto nos ecossistemas com o valor de referência (i.e. soma dos investimentos essenciais para a implantação do empreendimento, exceto investimentos voltados para a mitigação, custos, apólices e prêmios de seguros pessoais do empreendimento).

\subsection{ETAPA 2: CARACTERIZAÇÃO FÍSICA DA MICROBACIA HIDROGRÁFICA RIBEIRÃO DO FEIJÃO}

A microbacia hidrográfica do Ribeirão do Feijão está localizada entre os paralelos $22^{\circ} 00^{\prime}$ e $22^{\circ} 10^{\prime}$ de latitude sul e os meridianos $47^{\circ} 45^{\prime}$ e $45^{\circ} 50^{\prime}$ de longitude oeste, abrangendo os municípios de São Carlos, Itirapina e Analândia no interior do Estado de São Paulo, totalizando uma área de $222,7 \mathrm{Km}^{2}$. Provida de uma rica rede de drenagem (Figura 3), a vazão média da microbacia do Ribeirão do Feijão é de aproximadamente $0,246 \mathrm{~m}^{3} / \mathrm{s}$; o que classifica o Ribeirão do Feijão como um dos principais mananciais de abastecimento público para o município de São Carlos (MACHADO; DUPAS, 2013).

Figura 3 - Hidrografia da microbacia hidrográfica do Ribeirão do Feijão.

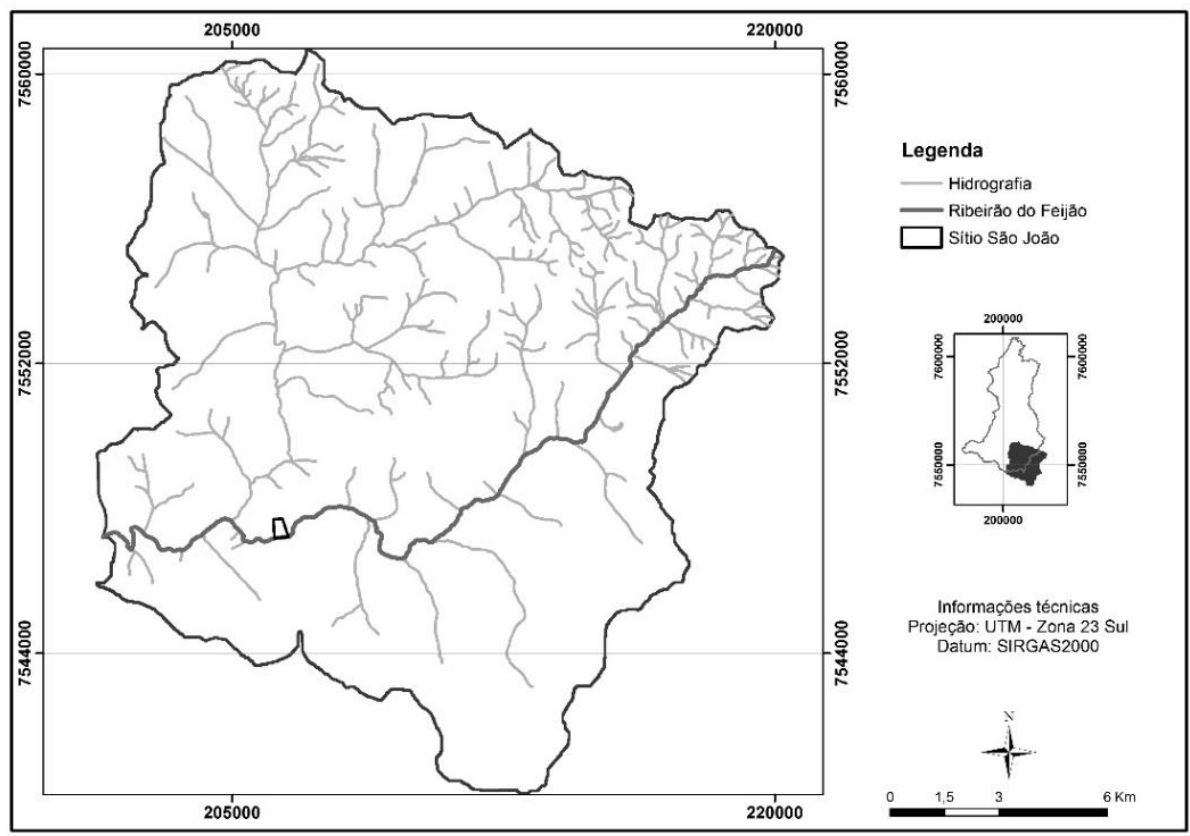

Fonte: Elaborado pelos autores. 
Não obstante, a microbacia hidrográfica do Ribeirão do Feijão é pouco declivosa (Figura 4), o que favorece a ocupação urbana e agrícola; representando uma ameaça à manutenção dos sistemas naturais na região. Aproximadamente, $60 \%$ do território total da microbacia encontram-se sobre áreas muito planas (declividade inferior a $5 \%$ ), onde são registrados processos deposicionais, os quais podem provocar o assoreamento dos corpos hídricos (TRENTIN; ROBAINA, 2005). Assim, a ocupação urbana e agrícola nestas áreas só é recomendável caso sejam aplicadas técnicas de conservação do solo e de manutenção dos sistemas naturais. É importante destacar ainda que o sítio São João está localizado sobre declividade inferior a 5\%, reforçando o interesse pela preservação da vegetação nativa na região.

Figura 4 - Declividade da microbacia hidrográfica do Ribeirão do Feijão.

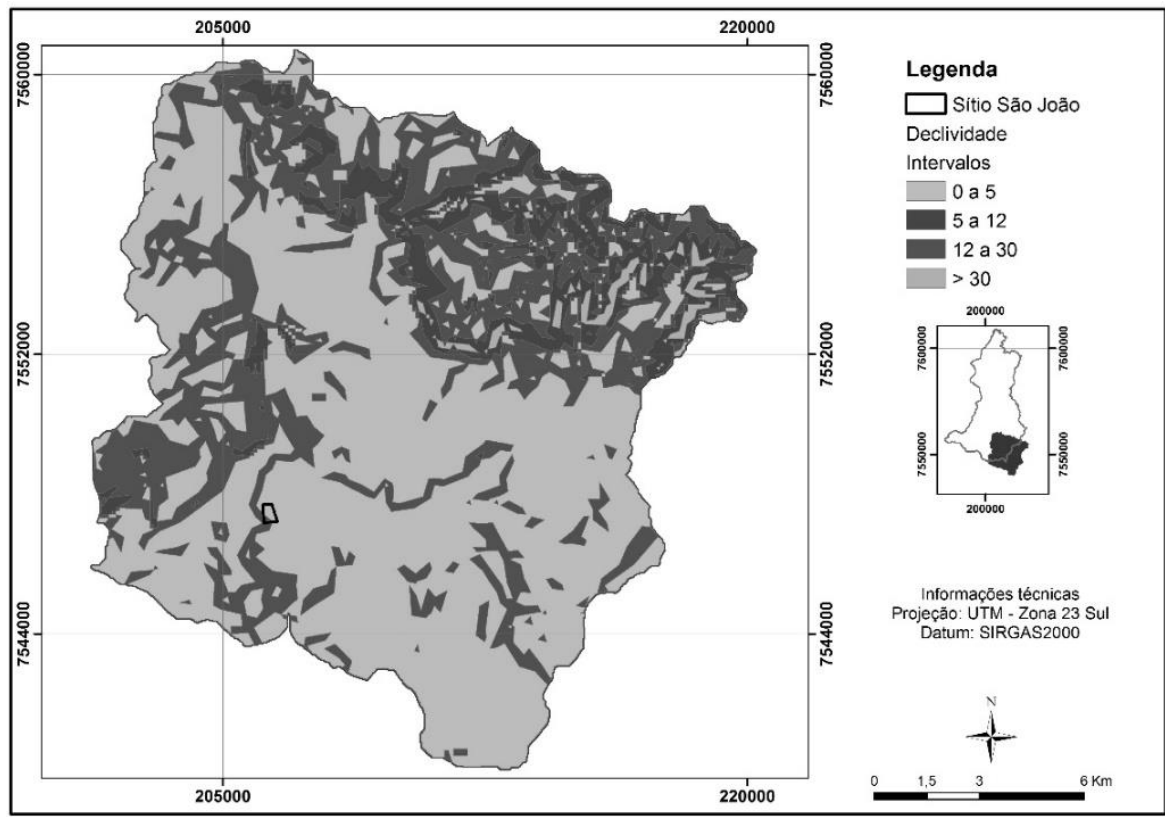

Fonte: Elaborado pelos autores.

As áreas onde a declividade do relevo encontra-se entre 5\% e $12 \%(9,6 \%$ do território total da microbacia) correspondem ao limite máximo de mecanização agrícola; ou seja, acima desse limiar, a compactação do solo e o nivelamento do terreno podem intensificar o processo de erosão. O limite máximo para a ocupação urbana, por sua vez, encontra-se no intervalo de $12 \%$ a $30 \%(29,2 \%$ do terreno), concentrando-se majoritariamente nas porções norte e oeste da microbacia em estudo.

Acima do limiar de $30 \%$ ( $1,2 \%$ do território), a exploração da terra só é permitida se sustentada por cobertura vegetal, uma vez que o corte raso da vegetação nestes locais impulsiona os processos de movimento de massa (BIASI, 1992). Além disso, é importante ressaltar que, de acordo com a Lei Federal $\mathrm{n}^{0}$ 12.651, de 25 de maio de 2012, as áreas com declividade superior a 45ำ são consideradas áreas de preservação permanente (APP). Portanto, é de fundamental 
importância a manutenção da vegetação nativa nessas regiões, sem qualquer tipo de interferência antrópica.

Verifica-se, entretanto, um avanço das atividades agrícolas na microbacia, principalmente sobre as áreas com declividade inferior a $12 \%$ (Figura 5). Ao todo, $73,1 \%$ do território total da microbacia são ocupados pela agricultura, sendo que $8 \%$ são destinados às lavouras permanentes; $41,6 \%$ às lavouras temporárias; $1,5 \%$ à silvicultura; $1,6 \%$ às áreas de pastagem; além dos 20,4\% das áreas descobertas, as quais podem ser consideradas como áreas sendo preparadas para o cultivo (Figura 6). Concomitantemente ao avanço da agricultura, ocorre a fragmentação da vegetação nativa, não somente nas áreas com declividade inferior a 12\%, mas na microbacia como um todo (Figura 7).

Figura 5 - Tipologias Ocupacionais da microbacia hidrográfica do Ribeirão do Feijão.

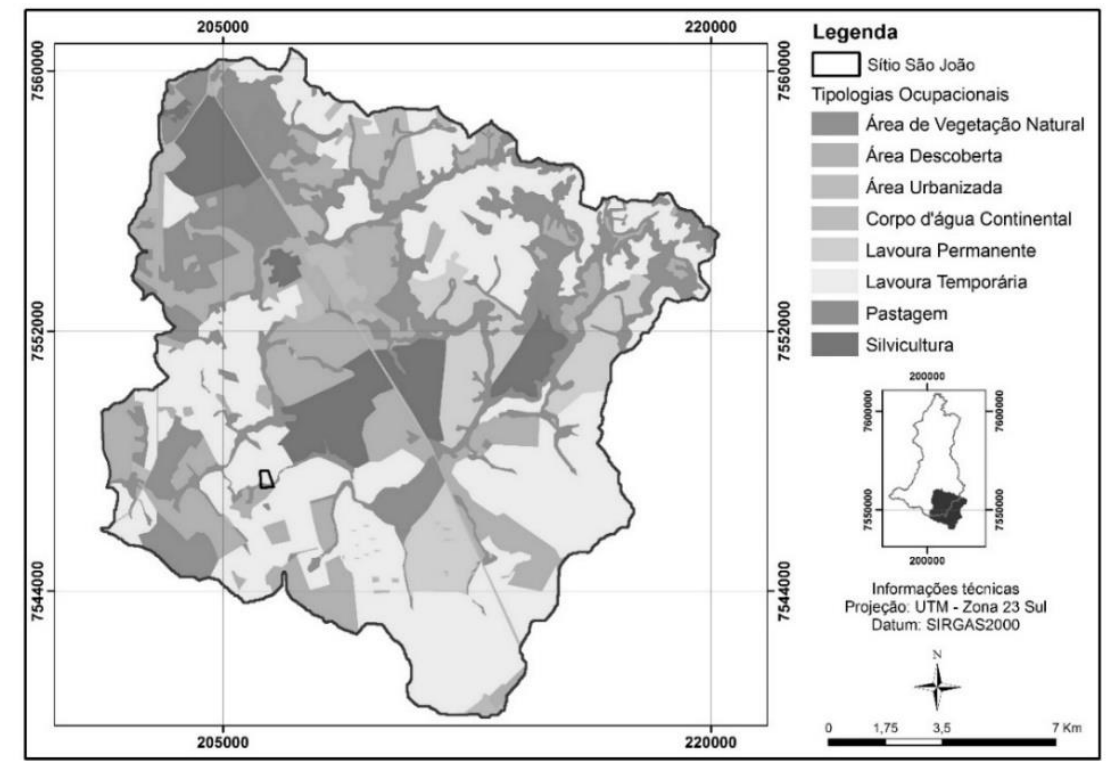

Fonte: Elaborado pelos autores. 
Figura 6 - Porcentagens das tipologias ocupacionais da microbacia do Ribeirão do Feijão.

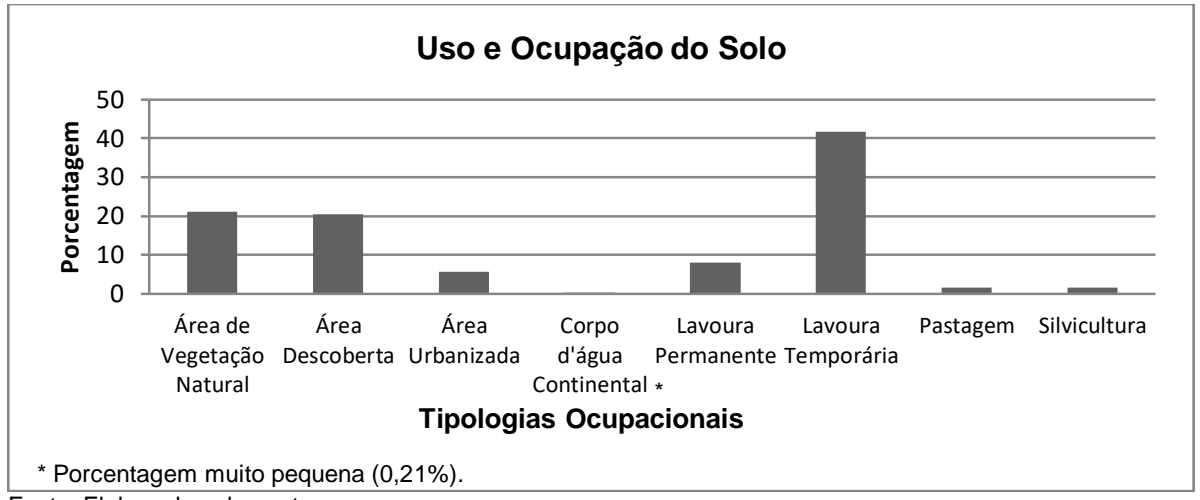

Fonte: Elaborado pelos autores.

Guidolini, Pedroso e Araújo (2013) constataram que entre os anos de 2005 e 2011 houve, na microbacia do Ribeirão do Feijão, uma substituição das áreas de mata ciliar, cerradão, reflorestamento e de pastagens, pelas áreas de cultivos e pela expansão urbana. Tal redução é refletida nos $21,1 \%$ do território total da microbacia que atualmente são ocupados por vegetação. Vale ressaltar que nas áreas onde a declividade do terreno é superior a 30\%, a vegetação nativa manteve-se preservada.

O sítio São João está localizado em uma importante área de conectividade entre fragmentos de vegetação na porção sul da microbacia (declividade inferior a $5 \%$ ) e fragmentos de vegetação na porção norte (declividade superior a $12 \%$ ). Todavia, este corredor de vegetação torna-se mais estreito em direção à porção sul, onde há maior pressão agrícola. Dessa forma, a fim de manter a funcionalidade desse sistema, é fundamental a permanência de reservas florestais nessa região.

Figura 7 - Cobertura vegetacional da microbacia hidrográfica do Ribeirão do Feijão.

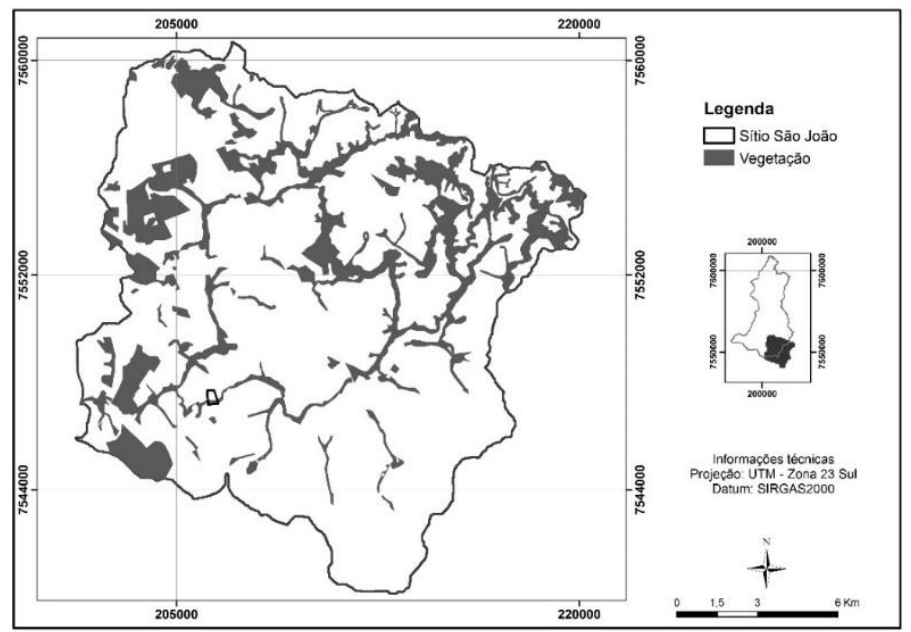

Fonte: Elaborado pelos autores. 


\subsection{ETAPA 3: ESTIMATIVA DO PSA PARA A RPPN DO SÍTIO SÃO JOÃO}

A área selecionada para tornar-se uma RPPN no sítio São João (Figura 08) corresponde a um fragmento de vegetação nativa que foi mantido e recuperado pelo proprietário do local. Ao todo são 4,76 hectares de área florestada. Este fragmento, tal como verificado na etapa de caracterização física da microbacia do Ribeirão do Feijão, possui a função de promover a conectividade entre fragmentos de vegetação presentes nas porções sul e norte da microbacia e, dessa forma, maximizar a conservação dos recursos bióticos e abióticos existentes na região. Além disso, enfatiza-se que esta área de vegetação nativa protege o manancial do Ribeirão do Feijão, contribuindo para a manutenção da qualidade do recurso hídrico. É importante ressaltar ainda que a vegetação nativa na região é categorizada como secundária de Floresta Ombrófila Mista, em transição com vegetação de Cerrado (FAPESP, 2016). A estimativa do valor do PSA para o sítio São João, portanto, foi realizada com base em tais características.

A estimativa do recebimento pela manutenção dos serviços ambientais foi baseada no cálculo do VRA e do PSA e nos valores do CV e UFESP, especificados na Resolução SMA no 89, de 18 de setembro de 2013 e no edital de chamada pública no 01/2013/CAP/RPPN, Processo SMA no 7.295/2012; tal como salientado anteriormente.

Como primeiro passo para a estimativa do PSA, tem-se o cálculo do valor de referência anual (VRA), que é o produto de três variáveis. A primeira delas diz respeito ao "Coeficiente de Valoração" (CV), que tem por finalidade ajustar o valor e a distribuição dos recursos, previamente definidos pelo próprio edital. De acordo com o Edital no 01/2013/CAP/RPPN, este valor equivale a 12.

Figura 8 - RPPN proposta para o sítio São João (área: 4,76 hectares).

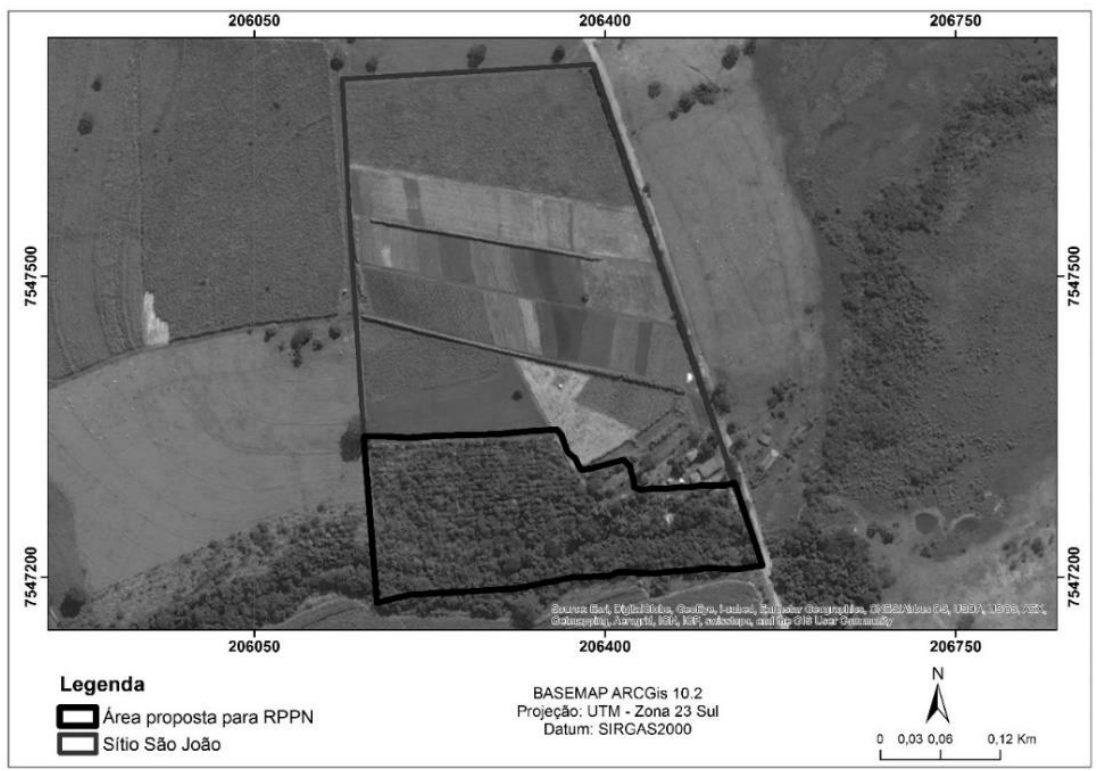

Fonte: Elaborado pelos autores. 
A segunda variável corresponde à "Unidade Fiscal do Estado de São Paulo" - UFESP que, para o ano de 2015, foi de R\$21,25. Para este trabalho adotou-se o valor da UFESP mais recente; quando houver nova chamada pública tal valor deve ser atualizado.

A terceira variável desta etapa é o "Fator RPPN", que, por sua vez, engloba duas sub variáveis: o fator de importância (Fimp) e o fator de ameaça (Fam). A chave para a determinação do fator de importância referente à RPPN do sítio São João está expressa na Tabela 02. Desse modo, considerando que o fragmento de vegetação em questão não se situa em área de cerrado (item a), mas que $100 \%$ da área passível de se tornar uma RPPN encontra-se inserida na Área de Proteção Ambiental (APA) Corumbataí-Botucatu-Tejupá, o fator de importância determinado foi de 0,8 .

Tabela 2 - Chave de determinação do fator de importância referente à RPPN.

\begin{tabular}{clccc}
\hline \multicolumn{5}{c}{ CHAVE DE DETERMINAÇÃO DO FATOR DE IMPORTÂNCIA } \\
\hline Item & Característica ambiental & Resposta & Ver item & Fator de Importância \\
\hline \multirow{2}{*}{ a } & Situado no Cerrado? & SIM & & 1,00 \\
\cline { 3 - 5 } & & NÃO & b & 0,8 \\
\cline { 2 - 5 } & $\begin{array}{l}\text { Mais de 50\% em Área de } \\
\text { Proteção Ambiental, Área de } \\
\text { Relevante Interesse }\end{array}$ & & & \\
Ecológico, Refúgio da Vida & NÃO & C & \\
& $\begin{array}{l}\text { Silvestre ou Monumento } \\
\text { Natural }\end{array}$ & & & \\
Fonte: Edital no 01/2013/CAP/RPPN (Adaptado).
\end{tabular}

O fator de ameaça (Fam) quantifica o esforço do proprietário em proteger e/ou mitigar danos aos serviços ambientais prestados pela RPPN - em função das ameaças às quais está submetida. A Tabela 03 expressa a pontuação atribuída às ameaças existentes sobre a RPPN. Os valores variam de zero (nenhuma ameaça) a um (todas as ameaças).

Tabela 3 - Pontuação atribuída às ameaças existentes.

\begin{tabular}{lc}
\hline Ameaças & Pontos \\
\hline Fogo & 0,2 \\
Áreas degradadas & 0,2 \\
Acesso indevido de terceiros & 0,2 \\
Acesso de animais domésticos & 0,2 \\
Superpopulação de espécies dominantes e presença de espécies com & 0,2 \\
potencial invasor &
\end{tabular}

Fonte: Edital nº 01/2013/CAP/RPPN (Adaptado).

Para a área de estudo, considerou-se como ameaça pertinente à RPPN somente o "acesso de animais domésticos" (valor 0,2), visto que estes foram observados na área durante visita ao local. Com relação às demais variáveis observou-se que não foram identificados cultivos próximos à área de interesse que dependessem de práticas de queima. Não foi diagnosticada a presença de estradas ou outros tipos de acesso fácil ao local, que pudessem induzir a entrada de terceiros. Não foram observadas também espécies invasoras dominantes na região; e, por fim, não foram verificadas áreas degradadas circunvizinhas ao fragmento de vegetação destinado à RPPN, as quais poderiam comprometer a integridade do 
mesmo. A soma total dos pontos (i.e. fator de ameaça), portanto, foi equivalente a 0,2 (i.e. apenas referente ao acesso de animais doméstico).

Dessa forma, o valor final obtido para o fator RPPN foi de 1,25; e, portanto, o VRA (VRA $=12 \times 21,25 \times 1,25)$ foi equivalente a 318,75.

$\mathrm{Na}$ segunda etapa da estimativa do valor do PSA, a área total da RPPN considerada (i.e. 4,76 hectares) foi dividida em classes de tamanho (CLASSE). O tamanho de cada CLASSE é estabelecido pelo edital. Para o sítio São João, onde a área da RPPN é inferior a cinco hectares, o valor da CLASSE correspondente é o de 100 hectares, para fins de realização dos cálculos. Se uma RPPN for maior que o valor máximo da $1^{\text {a }}$ CLASSE, uma segunda CLASSE será criada, e assim sucessivamente. Cada CLASSE tem um coeficiente de área $(\mathrm{Ca})$, também definido no edital. Para a primeira CLASSE, o coeficiente de área definido é 01 (i.e. o Ca da classe seguinte corresponderá sempre à metade do $\mathrm{Ca}$ anterior). A área de cada CLASSE é multiplicada, então, pelo seu respectivo coeficiente de área. No caso da RPPN do sítio São João, multiplicou-se a área de 4, 76 hectares por 01.

Dessa forma, o valor total a ser recebido por ano correspondente ao PSA é dado pela multiplicação do VRA $(318,75)$ pelo valor obtido na segunda etapa $(4,76)$. Caso a RPPN proposta fosse contemplada pelo programa de PSA, o valor a ser recebido para a manutenção dos serviços ambientais com a instituição da RPPN, e considerando o edital mais recente, seria de $R \$ 1.517,25$ por ano, durante o período estipulado pela chamada pública.

\section{CONSIDERAÇÕES FINAIS}

A criação de uma RPPN tem se mostrado uma alternativa viável quanto à gestão ambiental em terras privadas, enfatizando, principalmente, a proteção dos serviços ambientais (DOURADO; BOTELHO, 2015). Porém, a burocracia dos processos legais e a falta de incentivos por parte do poder público desestimulam os proprietários de terra a aderirem aos programas, dificultando a implantação das RPPN's. Além disso, verificou-se um processo lento com relação à abertura periódica dos editais, o que também contribui para o desestímulo dos proprietários interessados.

Com relação ao cálculo do valor do PSA, destacam-se alguns pontos importantes a serem revistos. Por exemplo, não houve menção ao bioma Mata Atlântica quando da leitura da chave de determinação do fator de importância. Tanto o Cerrado quanto a Mata Atlântica são considerados como Hotspots mundiais; ou seja, são áreas de alta biodiversidade, mas que se encontram fortemente degradadas (MYERS et al., 2000). O Estado de São Paulo é abrangido por estes dois Hotspots, além de algumas fitofisionomias serem classificadas como áreas de transição entre ambos. Assim, é necessário que para um programa de PSA destinado às RPPN's paulistas, tais características sejam levadas em consideração.

Com relação à RPPN proposta para o sítio São João, verificou-se que esta é viável e necessária, uma vez que possui a função de conectar fragmentos de vegetação localizados nas porções norte e sul da microbacia do Ribeirão do Feijão. Além disso, esta microbacia como um todo tem potencial para que outras RPPN's sejam instituídas, pois é uma área ambientalmente frágil e de grande importância econômica e social, principalmente quando se trata do abastecimento público do município de São Carlos.

Para que as RPPN's cumpram seus objetivos (i.e. ecológicos, sociais e econômicos), tornam-se necessários maiores esforços por parte do poder público em otimizar o processo de solicitação e implantação das mesmas. Além disso, é requerida uma maior fiscalização das unidades existentes, de modo a verificar a 
efetividade da aplicação do PSA para a manutenção destes sistemas. Universidades e órgãos governamentais devem orientar a elaboração dos planos de manejo e de gestão das RPPN's, visando à conservação da diversidade biológica regional, assim como a proteção dos serviços ambientais.

\section{REFERÊNCIAS}

BIASI, M. A carta clinográfica: os métodos de representação e sua confecção. Revista do Departamento de Geografia, São Paulo, v. 6, p. 31-42, 1992.

BRASIL. Lei $\mathrm{n}^{\circ}$ 9.985, de 18 de julho de 2000. Institui o Sistema Nacional de Unidades de Conservação da Natureza e dá outras providências. Disponível em: < http://www.planalto.gov.br/ccivil_03/leis/19985.htm>. Acesso em: 21 abr. 2015.

BRASIL. Decreto $n^{\circ} 6.848$ de 14 de maio de 2009. Altera e acrescenta dispositivos ao Decreto no 4.340, de 22 de agosto de 2002, para regulamentar a compensação ambiental. Disponível em:<http://www.planalto.gov.br/ccivil_03/_Ato2007-2010/2009/ Decreto/D6848. htm >. Acesso em: 3 mar. 2016.

BRASIL. Lei $\mathbf{n}^{\circ} \mathbf{1 2 . 6 5 1}$, de 25 de maio de 2012. Dispõe sobre a proteção da vegetação nativa; altera as Leis nos 6.938, de 31 de agosto de 1981, 9.393, de 19 de dezembro de 1996, e 11.428, de 22 de dezembro de 2006; revoga as Leis nos 4.771, de 15 de setembro de 1965, e 7.754, de 14 de abril de 1989, e a Medida Provisória no 2.166-67, de 24 de agosto de 2001; e dá outras providências. Disponível em:<http://www.planalto.gov.br/ccivil_03/_ato2011-2014/2012/lei/l12651. htm>. Acesso: em 2 mar. 2016.

CERETTA, C. C.; SANTOS, N. Z. O papel da extensão rural e a abordagem do turismo junto as pequenas propriedades rurais. Extensão Rural. Santa Maria, v. 20, n. 2, mai./ago. 2013.

CONAMA - Conselho Nacional de Meio Ambiente. Resolução CONAMA n 428, de 17 de dezembro de 2010. Dispõe, no âmbito do licenciamento ambiental sobre a autorização do órgão responsável pela administração da Unidade de Conservação (UC), de que trata o $\S 3^{\circ}$ do artigo 36 da Lei $n^{\circ} 9.985$ de 18 de julho de 2000, bem como sobre a ciência do órgão responsável pela administração da UC no caso de licenciamento ambiental de empreendimentos não sujeitos a EIA-RIMA e dá outras providências. Disponível em:<http://www.mma.gov.br/port/conama/legiabre.cfm? codlegi $=641>$. Acesso em: 3 mar. 2016.

DOURADO, G. F.; BOTELHO, M. I. V. As concepções de natureza e ambiente no semiárido brasileiro: contribuições da história ambiental. Extensão Rural. Santa Maria, v. 22, n. 4, out./dez. 2015.

EF - Escola da Floresta. Nossa história. Disponível em: $<$ http://www.escoladafloresta.com.br/educacao-ambiental/projetos/amigos-doribeirao-feijao/>. Acesso em: 16 abr. 2016.

EMBRAPA - Empresa Brasileira de Pesquisa Agropecuária. Serviços ambientais em sistemas e florestas do bioma Mata Atlântica. PARRON, L. M.; GARCIA, J. R.; OLIVEIRA, E. B.; BROWN, G. G.; PRADO, R. B. Organizadores - Brasília: EMBRAPA FLORESTAS, 2015. 
ENGEL, S.; PAGIOLA, S.; WUNDER, S. Designing payments for environmental services in theory and practice: An overview of the issues. Ecological Economics, v. 65, p. $663-674,2008$.

FAPESP - Fundação de Ampara à Pesquisa no Estado de São Paulo. SinBiota. Disponível em:<http://sinbiota.biota.org.br/atlas/>. Acesso em: 4 de mar. 2016.

FF - Fundação Florestal. Como criar uma RPPN. Disponível em: $<$ http://fflorestal.sp. gov.br/unidadesdeconservacao/rppn/rppncomocriar/>. Acesso em: jun. 2015.

FF - Fundação Florestal. Portaria Normativa ${ }^{\circ}$ 37, de 22 de fevereiro de 2007. Estabelece procedimentos para a criação das Reservas Particulares do Patrimônio Natural - RPPNs Estaduais. Disponível em: <http://www.rppnweb.com/site_rppn/index.php/biblioteca $\quad$-virtual/category/25legislacao-sp?download=47:portaria-normativa-n-37-de-22-de-fevereiro-de-2007>. Acesso em: 16 abr. 2015.

GUIDOLINI, J. F.; PEDROSO, L. B.; ARAÚJO, M. V. N. Análise temporal do uso e ocupação do solo na microbacia do Ribeirão do Feijão, município de São Carlos SP, entre os anos de 2005 e 2011. Anais. XVI Simpósio Brasileiro de Sensoriamento Remoto, Foz do Iguaçu. 2013.

IBAMA - Instituto Brasileiro do Meio Ambiente e dos Recursos Naturais Renováveis. Orientações e informações ao proprietário rural. Disponível em:<http://www. ibama.gov.br/servicos/ato-declaratorio-ambiental-ada>. Acesso em: 29 fev. 2016.

IBAMA - Instituto Brasileiro do Meio Ambiente e dos Recursos Naturais Renováveis. Instrução Normativa $\mathbf{n}^{\circ}$ 5, de 25 de março de 2009. Disponível em:<http://www. mma.gov.br/estruturas/pnf/_arquivos/in_ibama_5_2009_5.pdf>. Acesso em: 29 fev. 2016.

IBGE - Instituto Brasileiro de Geografia e Estatística. Manual técnico de uso da terra. 3a ed. Rio de Janeiro, 2013, p. 171. (Manuais Técnicos em Geociências, nº 7).

JACK, B. K.; KOUSKY, C.; SIMS, K. R. E. Designing payments for ecosystem services: Lessons from previous experience with incentive-based mechanisms. Proceedings of the National Academy of Sciences, v. 105, n. 28, p. 9465-9470, 2008.

MACHADO, F. H.; DUPAS, F. A. Valoração dos Recursos Hídricos como subsídio na gestão do manancial urbano do Ribeirão do Feijão, São Carlos - SP. Revista GEOUSP - espaço e tempo, São Paulo, n. 33, p. 111-126, 2013.

MA - MILLENNIUM ECOSYSTEM ASSESSMENT. Ecosystems and Human Wellbeing: Synthesis. Washington, DC: Island Press, 2005.

MMA - Ministério do Meio Ambiente. Unidades de conservação por bioma - 2015. Disponível em:<http://www.mma.gov.br/images/arquivo/80112/CNUC_Bioma_ Fevereiro_2015.pdf>. Acesso em: 4 mar. 2016. 
MYERS, N. et al. Biodiversity hotspots for conservation priorities. Nature, v. 403, n. 6772, p. 853-858, 2000.

PELLIN, A.; RANIERI, V. E. L. Motivações para o Estabelecimento de RPPNs e análise dos incentivos para sua criação e gestão no Mato Grosso do Sul. Natureza \& Conservação, v. 7, n. 2, p. 77-81, 2009.

SÃO PAULO. Decreto $n^{\circ} 51.150$, de 3 de outubro de 2006. Dispõe sobre o reconhecimento das Reservas Particulares do Patrimônio Natural, no âmbito do Estado de São Paulo, institui o Programa Estadual de Apoio às Reservas Particulares do Patrimônio Natural e dá providências correlatas. Disponível em: <http://fflorestal.sp.gov.br/files/2012/01/DecEst\%2051.150-06\%20RPPN\%20

Estadual.pdf >. Acesso em: 21 abr. 2015.

SÃO PAULO (a). Decreto Estadual $n^{\circ}$ 59.260, de 05 de junho de 2013. Institui o Programa Estadual de apoio financeiro a ações ambientais, denominado Crédito Ambiental Paulista. Disponível em:<http://www.al.sp.gov.br/repositorio/legislacao/ decreto/2013/decreto-59260-05 .06. 2013.html>. Acesso em: 16 abr. 2015.

SÃO PAULO (b). Resolução SMA n $^{\circ}$ 89, de 18 de setembro de 2013. Institui as diretrizes para a execução do Projeto de Pagamento por Serviços Ambientais para as Reservas Particulares do Patrimônio Natural - RPPN, no âmbito do Programa de Remanescentes Florestais. Disponível em: <http://www.ambiente.sp.gov.br/ legislacao/resoluçõessma/ Resolucaosma892013/>. Acesso em: 17 abr. 2015.

SCHENINI, P. C.; COSTA, A. M.; CASARIN, V. W. Unidades de Conservação: Aspectos Históricos e sua Evolução. Anais. Congresso Brasileiro de Cadastro Multifinalitário · UFSC, Florianópolis. 2004.

TRENTIN, R.; ROBAINA, L. E. S. Análise do relevo no alto curso da Bacia Hidrográfica do Rio Itu, RS. Interface, Porto Nacional (TO), v. 2, n. 2, p. 146-155, 2005.

WUNDER, S. Payments for environmental services: some nuts and bolts. CIFOR Occasional Paper, n. 42, p. 24, 2005. 